\title{
Partially dissecting the steady-state electron fluxes in Photosystem I in wild-type and pgr5 and ndh mutants of Arabidopsis
}

\author{
Jiancun Kou 1,2, Shunichi Takahashi' ${ }^{2}$, Da-Yong Fan ${ }^{2,3}$, Murray R. Badger ${ }^{2}$ and \\ Wah S. Chow ${ }^{2 *}$ \\ ${ }^{1}$ College of Animal Science and Technology, Northwest A\&F University, Yangling, China, ${ }^{2}$ Division of Plant Sciences, \\ Research School of Biology, The Australian National University, Canberra, ACT, Australia, ${ }^{3}$ State Key Laboratory of \\ Vegetation and Environmental Change, Institute of Botany, The Chinese Academy of Sciences, Beijing, China
}

\section{OPEN ACCESS}

Edited by:

Wei Huang,

Kunming Institute of Botany, Chinese Academy of Sciences, China

Reviewed by:

Stefano Santabarbara, Consiglio Nazionale delle Ricerche,

Mikko Tikkane University of Turku, Finland

*Correspondence:

Wah S. Chow,

Division of Plant Sciences, Research School of Biology, The Australian National University, Canberra,

ACT 2601, Australia

fred.chow@anu.edu.au

Specialty section:

This article was submitted to

Plant Physiology,

a section of the journal

Frontiers in Plant Science

Received: 31 May 2015 Accepted: 04 September 2015 Published: 17 September 2015

Citation:

Kou J, Takahashi S, Fan D-Y, Badger MR and Chow WS (2015)

Partially dissecting the steady-state electron fluxes in Photosystem I in wild-type and pgr5 and ndh

mutants of Arabidopsis.

Front. Plant Sci. 6:758.

doi: 10.3389/fp/s.2015.00758
Cyclic electron flux (CEF) around Photosystem I (PS I) is difficult to quantify. We obtained the linear electron flux ( $\left.\mathrm{LEF}_{\mathrm{O} 2}\right)$ through both photosystems and the total electron flux through PS I (ETR1) in Arabidopsis in $\mathrm{CO}_{2}$-enriched air. $\Delta$ Flux $=\mathrm{ETR} 1$ $\mathrm{LEF}_{\mathrm{O} 2}$ is an upper estimate of CEF, which consists of two components, an antimycin A-sensitive, PGR5 (proton gradient regulation 5 protein)-dependent component and an insensitive component facilitated by a chloroplastic nicotinamide adenine dinucleotide dehydrogenase-like complex (NDH). Using wild type as well as pgr5 and ndh mutants, we observed that (1) $40 \%$ of the absorbed light was partitioned to PS I; (2) at high irradiance a substantial antimycin A-sensitive CEF occurred in the wild type and the $n d h$ mutant; (3) at low irradiance a sizable antimycin A-sensitive CEF occurred in the wild type but not in the ndh mutant, suggesting an enhancing effect of $\mathrm{NDH}$ in low light; and (4) in the pgr5 mutant, and the wild type and ndh mutant treated with antimycin A, a residual $\Delta$ Flux existed at high irradiance, attributable to charge recombination and/or pseudo-cyclic electron flow. Therefore, in low-light-acclimated plants exposed to high light, $\Delta$ Flux has contributions from various paths of electron flow through PS I.

Keywords: antimycin A, Arabidopsis, cyclic electron flow, ndh mutant, P700, pgr5 mutant, photosystem I

\section{Introduction}

Arnon et al. (1955) demonstrated photophosphorylation via a (CEF) around Photosystem I (PS I) by illuminating isolated thylakoids in the presence of vitamin K. Supply of ATP is one of the factors that limit photosynthesis, such that increasing cyclic photophosphorylation helps to increase photosynthetic rate (Shen, 1990). Since CEF is essential for efficient photosynthesis (Munekage et al., 2004) and for photoprotection (Munekage et al., 2002;

\footnotetext{
Abbreviations: ATP, adenosine triphosphate; CEF, cyclic electron flux around Photosystem I; Chl, chlorophyll; ETR1, the total electron transport rate through PS I; $\triangle$ Flux, the difference between ETR1 and $\mathrm{LEF}_{\mathrm{O} 2} ; f_{\mathrm{I}}$, the fraction of absorbed light partitioned to PS I; $\mathrm{LEF}_{\mathrm{O} 2}$, the linear electron flux through PS II estimated by gross $\mathrm{O}_{2}$ evolution; $\mathrm{NDH}$, nicotinamide adenine dinucleotide dehydrogenase-like complex; P700, special chlorophyll dimer acting as the primary electron donor in PS I; PAM, pulse amplitude modulation fluorometer; PGR5, proton gradient regulation 5 protein; PGRL1, PGR5-like protein 1; PS I, Photosystem I; $\mathrm{PQH}_{2}$, plastoquinonol; PTOX, plastid terminal oxidase; $\mathrm{Y}(\mathrm{I})$, photochemical yield of PS I; $\mathrm{Y}(\mathrm{NA})$ and $\mathrm{Y}(\mathrm{ND})$, non-photochemical yield due to acceptor-side and donor-side limitation, respectively.
} 
Takahashi et al., 2009; Huang et al., 2011), there have been sustained efforts to elucidate the mechanisms and roles of this cyclic electron flow (for reviews, see Bendall and Manasse, 1995; Allen, 2003; Bukhov and Carpentier, 2004; Johnson, 2005; Joliot and Joliot, 2006; Shikanai, 2007, 2014; Alric, 2010; Miyake, 2010; Kramer and Evans, 2011; Leister and Shikanai, 2013; Johnson et al., 2014).

In flowering plants, cyclic electron flow consists of two pathways: one dependent on a PGR5-PGRL1 protein interaction (i.e., interaction between the proton gradient regulation 5 protein and the PGR5-like protein 1) and the other on a chloroplastic nicotinamide adenine dinucleotide dehydrogenase-like complex (NDH) complex. It is likely that the PGR5-PGRL1-dependent pathway, inhibitable by antimycin $\mathrm{A}$, corresponds to the cyclic photophosphorylation discovered by Arnon et al. (1955). Indeed, Hertle et al. (2013) showed that PGRL1 accepts electron from reduced ferredoxin in a PGR5-dependent manner and reduces quinones in an antimycin A-sensitive manner, proposing that PGRL1 is the elusive ferredoxin-plastquinone reductase. In the absence of PGR5, the chloroplast NDH-dependent pathway compensates for the loss of the important pathway to some extent (Munekage et al., 2004; Shikanai, 2014). For example, NDH may contribute to redox homeostasis in chloroplasts at low irradiance (Shikanai, 2014). Specifically, the NDH complex improves CEF by adjusting the redox level of electron carriers in low light (Martin et al., 2015).

Nevertheless, the involvement of these complexes in cyclic electron flow is complex. Even the antimycin A-sensitive pathway itself is still controversial (Leister and Shikanai, 2013). For example, there was some doubt as to whether the PGR5 protein is essential for cyclic electron flow at all (Nandha et al., 2007), though the technique for assaying CEF may be problematic (Leister and Shikanai, 2013). Certainly, understanding CEF has been hampered by the difficulty of quantifying CEF in vivo in physiological conditions due to the absence of a net product of cyclic electron flow. Methods for measuring/inferring CEF have all suffered from deficiencies. Kou et al. (2013) used a method that (a) estimates the total electron flux through PS I (ETR1) from the PS I photochemical yield, and the linear electron flux through both photosystems from the gross rate of oxygen evolution $\left(\mathrm{LEF}_{\mathrm{O} 2}\right)$ under identical illumination, both being whole-tissue measurements; (b) uses white actinic light to simulate sunlight, since colored light alters CEF; (c) took note of the important finding that a proper determination of the photochemical yield of PS I for calculating the total electron flux through PS I requires strong far-red light immediately before and during the application of a saturating light pulse (Siebke et al., 1997); and (d) is non-intrusive. This method is not yet ideal, being applicable only to $\mathrm{CO}_{2}$-enriched air, but it yields a reasonable quantitative estimate of CEF in spinach leaf disks from glasshouse plants.

In this study, the same method was applied to leaf disks of Arabidopsis plants grown in low-light in a controlledenvironment chamber. We used wild-type as well as pgr5 and $n d h$ mutants, in the absence or presence of antimycin A. The aim of this study was to attempt to semi-quantitatively dissect the electron fluxes that pass through PS I at varied irradiance.

\section{Materials and Methods}

\section{Plant Growth}

Arabidopsis thaliana wild-type (ecotype Columbia) and pgr5 and $n d h$ mutants were grown in a controlled-environment chamber at an irradiance of $100 \mu \mathrm{mol}$ photons $\mathrm{m}^{-2} \mathrm{~s}^{-1}$ at $22^{\circ} \mathrm{C}$, with a light/dark cycle of $10 / 14 \mathrm{~h}$ at $22^{\circ} \mathrm{C}$. At 3-4 weeks from germination, fully expanded leaves were used for experiments.

\section{Vacuum Infiltration of Leaf Disks}

When required, leaf disks $\left(1.5 \mathrm{~cm}^{2}\right)$ were immersed in water containing $0.2 \%$ dimethylsulfoxide or a $200 \mu \mathrm{M}$-solution of antimycin A with $0.2 \%$ dimethylsulfoxide carried over from the undiluted stock solution, vacuum-infiltrated using a water-driven pump for about $30 \mathrm{~s}$, blotted with absorbent paper, and allowed to evaporate off the excess intercellular water in darkness for a total of $30 \mathrm{~min}$ before measurement.

\section{Linear Electron Flux Measured by $\mathbf{O}_{2}$ Evolution}

$\mathrm{O}_{2}$ evolution was measured in a gas-phase oxygen electrode (Hansatech, King's Lynn, UK) chamber, thermostated at $25^{\circ} \mathrm{C}$, that accepted a multifurcated light guide with five arms, and contained $1 \% \mathrm{CO}_{2}$ supplied by fabric matting moistened with $1 \mathrm{M} \mathrm{NaHCO}_{3} / \mathrm{Na}_{2} \mathrm{CO}_{3}(\mathrm{pH}$ 9). White incandescent light from a projector halogen lamp filtered by a Calflex $\mathrm{C}$ heat-reflecting filter (Linos Photonics, Göttingen, Germany) and neutral-density filters was used to illuminate a leaf disk. $\mathrm{O}_{2}$ evolution was measured over several minutes until steady state. The postillumination drift was subtracted algebraically from the steadystate net oxygen evolution rate, and the gross oxygen evolution rate so obtained was multiplied by four to give the linear electron flux, $\mathrm{LEF}_{\mathrm{O} 2}$. For calibration of the oxygen signals, $1 \mathrm{~mL}$ of air at $25^{\circ} \mathrm{C}$ (taken to contain $8.05 \mu \mathrm{mol} \mathrm{O}_{2}$ ) was injected into the gas-phase $\mathrm{O}_{2}$ electrode chamber.

\section{Measurement of Redox Kinetics of P700}

Redox changes of P700, the special Chl dimer acting as the primary electron donor in PS I, were observed with a dual wavelength $(820 / 870 \mathrm{~nm})$ unit (ED-P700DW) attached to a PAM fluorometer (Walz, Effeltrich, Germany) in the reflectance mode (response time constant $=95 \mu \mathrm{s}$ ), as described by Kou et al. (2013). Lights and signals were transmitted through the multifurcated light guide inserted into the oxygen electrode. Before measurements, a leaf disk was brought to steady-state photosynthesis by illuminating it with white actinic light for about 10 min during which $\mathrm{O}_{2}$ evolution was measured. To retain steady state illumination for $\mathrm{P} 700^{+}$measurements, immediately after $\mathrm{O}_{2}$ measurement, each leaf disk was re-illuminated with the same actinic light for $9.016 \mathrm{~s}$, using an electronic shutter controlled by one terminal of a pulse/delay generator (Model 565, Berkeley Nucleonics, USA). In this way, oxygen evolution and P700 redox kinetics were measured sequentially, both during steady-steady actinic illumination at a selected irradiance, under identical conditions in $1 \% \mathrm{CO}_{2}$ and at $25^{\circ} \mathrm{C}$. To improve the $\mathrm{P} 700^{+}$signal-to-noise ratio, the 9.016-s illumination was repeated nine times, with $<0.88 \mathrm{~s}$ dark time between repeats so 
as maintain steady state photosynthesis, as described by Kou et al. (2013).

Near the end of each 9.016-s illumination, data acquisition by a computer program was initiated by a trigger pulse from another terminal of the pulse/delay generator, followed $(50 \mathrm{~ms}$ later) by the firing of an LED far-red pulse $(\sim 800 \mu \mathrm{mol}$ photons $\left.\mathrm{m}^{-2} \mathrm{~s}^{-1}\right)$ to oxidize the inter-system electron carriers with a duration of $100 \mathrm{~ms}$ during which was added a saturating pulse of white LED light ( $~ 9000 \mu \mathrm{mol}$ photons $\mathrm{m}^{-2} \mathrm{~s}^{-1}, 10 \mathrm{~ms}$ duration) to maximally oxidize all the P700 that can be oxidized while the actinic light was on. On application of the two pulses, the $\mathrm{P} 700^{+}$signal height reached the level $P_{\mathrm{m}}{ }^{\prime}$ in the presence of actinic light. In a separate measurement afterward, continuous weak far-red light $\left(\sim 50 \mu \mathrm{mol}\right.$ photons $\left.\mathrm{m}^{-2} \mathrm{~s}^{-1}\right)$ was applied to oxidize $\sim 85 \%$ of the P700; then a saturating xenon flash was given to oxidize the remaining $\mathrm{P} 700$, giving the maximum signal height $\left(P_{\mathrm{m}}\right)$ in the presence of weak far-red light. The height of the $\mathrm{P} 700^{+}$signal in actinic light, before the application of farred and white saturating pulses, is denoted as $a$, the increase in the $\mathrm{P}^{+} 00^{+}$signal height on application of the two pulses as $b$, and $\left(P_{\mathrm{m}}-P_{\mathrm{m}}{ }^{\prime}\right)$ as $c$ (see Klughammer and Schreiber, 2008). Thus, the photochemical yield of PS I, Y(I), was measured as described by Kou et al. (2013) by a slight modification of the method of Klughammer and Schreiber (2008) by adding a strong far-red pulse. Following Klughammer and Schreiber (2008), the photochemical yield of PS I is $\mathrm{Y}(\mathrm{I})=b /(a+b+c)$, averaged over closed PS I traps (containing $\mathrm{P}^{+} 00^{+}$) and open PS I traps (containing P700). The non-photochemical yield due to donor-side limitation is $\mathrm{Y}(\mathrm{ND})=a /(a+b+c)$ and the non-photochemical yield due to acceptor-side limitation is $\mathrm{Y}(\mathrm{NA})=c /(a+b+c) . \mathrm{Y}(\mathrm{I})+\mathrm{Y}(\mathrm{ND})+\mathrm{Y}(\mathrm{NA})=1$

The total electron flux through PS I, ETR1, was calculated as

$$
\mathrm{ETR} 1=\mathrm{Y}(\mathrm{I}) \times I \times 0.85 \times f_{\mathrm{I}}
$$

where $I$ is the irradiance, 0.85 is the assumed absorptance of the leaf disk and $f_{\mathrm{I}}$ is the fraction of absorbed white light partitioned to PS I. An experimental estimation of $f_{\mathrm{I}}$ at low irradiance and in the presence of antimycin A is given in Table $\mathbf{1}$.

\section{Results and Discussion}

The approach taken in this study has been to obtain the steadystate electron flux through PS I (ETR1) via the $\mathrm{P} 700^{+}$signal and the linear electron flux through both photosystems by oxygen evolution $\left(\mathrm{LEF}_{\mathrm{O} 2}\right)$, at $25^{\circ} \mathrm{C}$, in broad-spectrum white incandescent light and $\mathrm{CO}_{2}$-enriched air. The total electron flux through PS I and the linear electron flux were compared under identical conditions, both being whole-tissue measurements.

\section{Estimation of the Fraction of Absorbed Light $\left(f_{1}\right)$ Partitioned to PS I}

To estimate the total electron flux through PS I according to Equation 1, it is necessary to estimate $f_{\mathrm{I}}$, the fraction of absorbed light partitioned to PS I. To estimate $f_{\mathrm{I}}$, we consider some special cases in which (a) CEF, (b) direct charge recombination in the PS I reaction center and (c) pseudo-cyclic electron flow
TABLE 1 | Estimation of the fraction of absorbed light $\left(f_{1}\right)$ partitioned to PS I.

\begin{tabular}{|c|c|c|c|c|}
\hline $\begin{array}{l}\text { Leaf disks } \\
\text { (+antimy. A) }\end{array}$ & 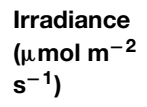 & $\mathbf{Y}(\mathbf{I})$ & $\begin{array}{l}\text { LEFo2 }_{02} \\
\left(\mu \mathrm{mol} \mathrm{e}^{-}\right. \\
\left.\mathrm{m}^{-2} \mathrm{~s}^{-1}\right)\end{array}$ & $f_{1}$ \\
\hline \multirow[t]{4}{*}{ Wild type } & 135 & $0.746 \pm 0.020$ & $33.1 \pm 1.5$ & 0.39 \\
\hline & 203 & $0.563 \pm 0.029$ & $41.0 \pm 2.3$ & 0.42 \\
\hline & 265 & $0.488 \pm 0.031$ & $40.6 \pm 0.8$ & 0.37 \\
\hline & & & & $A v=0.39$ \\
\hline \multirow[t]{4}{*}{ pgr5 } & 135 & $0.569 \pm 0.037$ & $27.4 \pm 1.4$ & 0.42 \\
\hline & 203 & $0.507 \pm 0.022$ & $35.5 \pm 2.0$ & 0.41 \\
\hline & 265 & $0.475 \pm 0.017$ & $37.8 \pm 1.8$ & 0.35 \\
\hline & & & & $A v=0.39$ \\
\hline \multirow[t]{4}{*}{ ndh } & 135 & $0.620 \pm 0.060$ & $28.8 \pm 3.0$ & 0.40 \\
\hline & 203 & $0.506 \pm 0.054$ & $31.8 \pm 2.5$ & 0.36 \\
\hline & 265 & $0.439 \pm 0.020$ & $34.9 \pm 2.4$ & 0.35 \\
\hline & & & & $A v=0.37$ \\
\hline
\end{tabular}

$Y(I)$ is the photochemical yield of $P S I$, and $L E F_{\mathrm{O} 2}$ is the linear electron flux determined by the gross rate of $\mathrm{O}_{2}$ evolution. Values are mean $\pm S E$. ( $n=4$ leaf disks for the wild type, seven for pgr5, and three for the ndh mutant). The value of $f_{\mathrm{l}}$ is estimated from $L E F_{\mathrm{O} 2}=Y(I) \times I \times 0.85 \times f_{\mathrm{l}}$, where $I$ is irradiance, assuming that there is neither CEF nor charge recombination at low irradiance combined with infiltration with a solution of $200 \mu \mathrm{M}$ antimycin $\mathrm{A}$. Av = Average.

associated with the water-water cycle initiated by the Mehler reaction are likely to be small or negligible. We assume that these conditions are approximately met when both (1) the irradiance is low (below $265 \mu \mathrm{mol}$ photons $\mathrm{m}^{-2} \mathrm{~s}^{-1}$ ) and (2) antimycin A is present. Under this assumption, we equate $\mathrm{LEF}_{\mathrm{O} 2}$ with ETR1 $\left[=\mathrm{Y}(\mathrm{I}) \times I \times 0.85 \times f_{\mathrm{I}}\right]$ to obtain $f_{\mathrm{I}}$. It is seen that at three low irradiances, $f_{\mathrm{I}}$ averaged to be slightly below 0.4 , in the wild type as well as in the pgr5 and $n d h$ mutants (Table 1). For simplicity, we took $f_{\mathrm{I}}$ to be 0.4 , which is close to the values obtained at the lowest irradiance. Further, we assume that the partitioning of absorbed energy did not change at higher irradiances. In spinach, this appeared to be the case: $f_{\mathrm{I}}$ was $\sim 0.48$ at an irradiance of $980 \mu \mathrm{mol}$ photons $\mathrm{m}^{-2} \mathrm{~s}^{-1}$ in the presence of antimycin $\mathrm{A}$, and about 0.47 at an irradiance $\leq 352 \mu \mathrm{mol}$ photons $\mathrm{m}^{-2} \mathrm{~s}^{-1}$ in the absence of antimycin A (Kou et al., 2013).

\section{Wild Type}

In the absence of antimycin A, ETR1 (the total electron flux through PS I), calculated by assuming $f_{\mathrm{I}}=0.4$, did not show saturation even at the highest irradiance of white light used (Figure 1A). By contrast, $\mathrm{LEF}_{\mathrm{O} 2}$, assayed as the gross rate of $\mathrm{O}_{2}$ evolution multiplied by 4 , almost peaked at about $250 \mu \mathrm{mol}$ photons $\mathrm{m}^{-2} \mathrm{~s}^{-1}$, showing a slight increase at higher irradiances. The maximum $\mathrm{LEF}_{\mathrm{O} 2}$ reached about $50 \mu \mathrm{mol}$ electrons $\mathrm{m}^{-2} \mathrm{~s}^{-1}$ (gross $\mathrm{O}_{2}$ evolution rate, about $12 \mu \mathrm{mol} \mathrm{m} \mathrm{m}^{-2} \mathrm{~s}^{-1}$ ). The difference between ETR1 and $\mathrm{LEF}_{\mathrm{O} 2}(=\Delta$ Flux $)$ increased approximately linearly with irradiance, even at low irradiance (Figure 1A). At the highest irradiance, $\Delta$ Flux exceeded $\mathrm{LEF}_{\mathrm{O} 2}$.

Wild type Arabidopsis grown in low light in a controlled chamber in this study behaved differently from spinach grown in a glasshouse. In spinach, $\mathrm{LEF}_{\mathrm{O} 2}$ did not reach a maximum until the irradiance was about $1500 \mu \mathrm{mol}$ photons $\mathrm{m}^{-2} \mathrm{~s}^{-1}$; consequently, ETR1 and LEFO2 were approximately equal until 
the irradiance exceeded about $300 \mu$ mol photons $\mathrm{m}^{-2} \mathrm{~s}^{-1}$, above which $\Delta$ Flux increased approximately linearly (Kou et al., 2013). Therefore, whether a substantial $\Delta$ Flux exists at low irradiance appears to depend on how easily $\mathrm{LEF}_{\mathrm{O} 2}$ is saturated by light.

As the irradiance increased, P700 in wild-type Arabidopsis became more and more oxidized; consequently, fewer and fewer PS I complexes were able to perform charge separation because of the limitation due to $\mathrm{P} 700^{+}$on the donor side. Thus, the nonphotochemical yield of PS I due to limitation on the donor side when P700 is oxidized, Y(ND), increased steadily with irradiance (Figure 1B). Interestingly, as the irradiance increased, the nonphotochemical yield of PS I due to limitation on the acceptor side when the acceptors are reduced, Y(NA), first increased, and then declined above $559 \mu \mathrm{mol} \mathrm{m} \mathrm{m}^{-2} \mathrm{~s}^{-1}$. That is, at a high irradiance, electron carriers on the acceptor side seemed to be more oxidized. The enhanced oxidation of electron carriers on the acceptor side above $559 \mu \mathrm{mol} \mathrm{m} \mathrm{m}^{-2} \mathrm{~s}^{-1}$ probably resulted from a number of factors. One factor could be the hastening of downstream processes such as carbon assimilation, consistent with a further slight increase in $\mathrm{LEF}_{\mathrm{O} 2}$ above $559 \mu \mathrm{mol} \mathrm{m}^{-2} \mathrm{~s}^{-1}$ (Figure 1A). Other possible factors are discussed immediately below.

The steady increase of $\Delta$ Flux with irradiance could have at least three components. One is CEF that feeds electrons back to the PQ pool to be cycled through PS I. A second component is charge recombination: an electron on the acceptor side could recombine with $\mathrm{P} 700^{+}$on the donor side in a kind of short cycle, but this electron has had to be transferred through PS I in the first place, so it should be counted as part of the electron flux through PS I. A third component is the waterwater cycle; although a complete water-water cycle leads to no net release or uptake of $\mathrm{O}_{2}$ and so does not affect the measurement of LEF $_{\mathrm{O} 2}$ (Miyake, 2010), ETR1 should include (pseudo-cyclic) electron flow associated with the water-water cycle. Thus, $\Delta$ Flux $=$ ETR1 $-\mathrm{LEF}_{\mathrm{O} 2}$ does include any pseudo-cyclic electron flux. As the irradiance increased, the observation that $\Delta$ Flux increased (Figure 1A) while Y(NA) decreased (Figure 1B) could come about if CEF, charge recombination and/or pseudo-cyclic electron flow increased, thereby alleviating the acceptor side limitation.

In the presence of antimycin $A$, the antimycin A-sensitive component of CEF should have been largely inhibited. Below $265 \mu$ mol photons $\mathrm{m}^{-2} \mathrm{~s}^{-1}$, ETR1 and $\mathrm{LEF}_{\mathrm{O} 2}$ were similar in magnitude (Figure 2A). Presumably below this irradiance, there was little or no pseudo-cyclic electron flux or charge recombination. Above this irradiance, however, $\Delta$ Flux increased steadily. Given that the acceptor side limitation was quite high at high irradiance, $\mathrm{Y}(\mathrm{NA})$ being $\sim 0.55$, it is likely there was enhanced charge recombination and/or pseudo-cyclic electron flow due to a more reduced state of electron carriers on the acceptor side of PS I. Increased charge recombination might have been the more important of the two components of the electron flux in this situation: P700 was kept more reduced [lower $\mathrm{Y}(\mathrm{ND})$, Figure 2B] compared with the absence of antimycin A (Figure 1B), presumably by charge recombination, whereas pseudocyclic electron flow should have kept P700 more oxidized. Thus, it appears that inhibition of CEF by antimycin A resulted in a more reduced acceptor side, which in turn enhanced charge recombination and, potentially, also pseudo-cyclic electron flow at high irradiance.

It should be noted that low-light-grown plants such as those used in this study may be particularly prone to charge recombination when exposed to an irradiance 10-fold greater than their growth irradiance. They have neither the photosynthetic capacity to utilize the abundant photons nor the photoprotective capacity to dissipate excess excitation safely as heat. Consequently, charge recombination in PS I may be enhanced. In such low-light-grown plants, the low linear electron transport capacity would be readily saturated, accompanied by a low rate of carbon assimilation and any cyclic electron flux that occurred. Any excess electrons accumulating on the acceptor side of PS I would return to the donor side in a kind of a futile short circuit at the end of a linear chain and would constitute a component of $\Delta$ Flux not inhibited by antimycin $\mathrm{A}$. This contrasts with glasshouse grown spinach which, in high light, has only a very small remaining $\Delta$ Flux in the presence of antimycin $\mathrm{A}$ (Kou et al., 2013).

\section{The pgr5 Mutant}

In the absence of antimycin $A$, the pgr5 mutant showed a $\Delta$ Flux that only increased slowly with increase in irradiance (Figure 3A). For example, $\Delta$ Flux was only $4.7 \mu \mathrm{mol}$ electrons $\mathrm{m}^{-2} \mathrm{~s}^{-1}$ at the irradiance $559 \mu \mathrm{mol}$ photons $\mathrm{m}^{-2} \mathrm{~s}^{-1}$. This seems surprising, given that the acceptor side was highly reduced, Y(NA) being 0.73 (Figure 3B), which should have favored charge recombination and pseudo-cyclic electron flow. Probably, however, charge recombination could not occur because P700 was almost completely reduced and there was hardly any $\mathrm{P}^{2} 00^{+}$ available for charge recombination. That is, the near-zero $\mathrm{Y}(\mathrm{ND})$ may be the reason for the very small $\Delta$ Flux at 559 above $559 \mu \mathrm{mol}$ photons $\mathrm{m}^{-2} \mathrm{~s}^{-1}$. Further, this small $\Delta$ Flux, with a magnitude that was about $10 \%$ of $\mathrm{LEF}_{\mathrm{O} 2}$, also implies that pseudo-cyclic electron transfer was not very active at this irradiance despite the highly reduced state of the acceptor side.

Similarly, in the pgr5 mutant at $1120 \mu \mathrm{mol}$ photons $\mathrm{m}^{-2}$ $\mathrm{s}^{-1}$, the acceptor side was highly reduced and the donor side completely reduced (Figure 3B). At this irradiance, by contrast, $\Delta$ Flux was $47 \mu \mathrm{mol}$ electrons $\mathrm{m}^{-2} \mathrm{~s}^{-1}$. At double the irradiance, many more excess electrons had to be discharged by either charge recombination or pseudo-cyclic electron transport in the form of increased $\Delta$ Flux $\left(=47 \mu \mathrm{mol}\right.$ electrons $\left.\mathrm{m}^{-2} \mathrm{~s}^{-1}\right)$, but even so, $\mathrm{Y}(\mathrm{NA})$ and $\mathrm{Y}(\mathrm{ND})$ were each similar at 559 and $1120 \mu \mathrm{mol}$ photons $\mathrm{m}^{-2} \mathrm{~s}^{-1}$ (Figure 3B).

In the presence of antimycin $A$, the pgr5 mutant (Figure 4A) behaved in a rather similar fashion as the wild type treated with antimycin A (Figure 2A) in response to increase in irradiance. In both cases, there was little or no $\Delta$ Flux below about $200 \mu \mathrm{mol}$ photons $\mathrm{m}^{-2} \mathrm{~s}^{-1}$. This result implies that the $\Delta$ Flux $\approx 18 \mu \mathrm{mol}$ electrons $\mathrm{m}^{-2} \mathrm{~s}^{-1}$ observed in the wild type in the absence of antimycin A (Figure 1A) at irradiance 135-203 $\mu \mathrm{mol}$ photons $\mathrm{m}^{-2} \mathrm{~s}^{-1}$ was due to antimycin A-sensitive CEF, the magnitude of which can be compared with the $\mathrm{LEF}_{\mathrm{O} 2}$ values: $23 \mu$ mol electrons $\mathrm{m}^{-2} \mathrm{~s}^{-1}$ at $135 \mu \mathrm{mol}$ photons $\mathrm{m}^{-2} \mathrm{~s}^{-1}$, and $34 \mu \mathrm{mol}$ electrons $\mathrm{m}^{-2} \mathrm{~s}^{-1}$ at $203 \mu \mathrm{mol}$ photons $\mathrm{m}^{-2} \mathrm{~s}^{-1}$. 


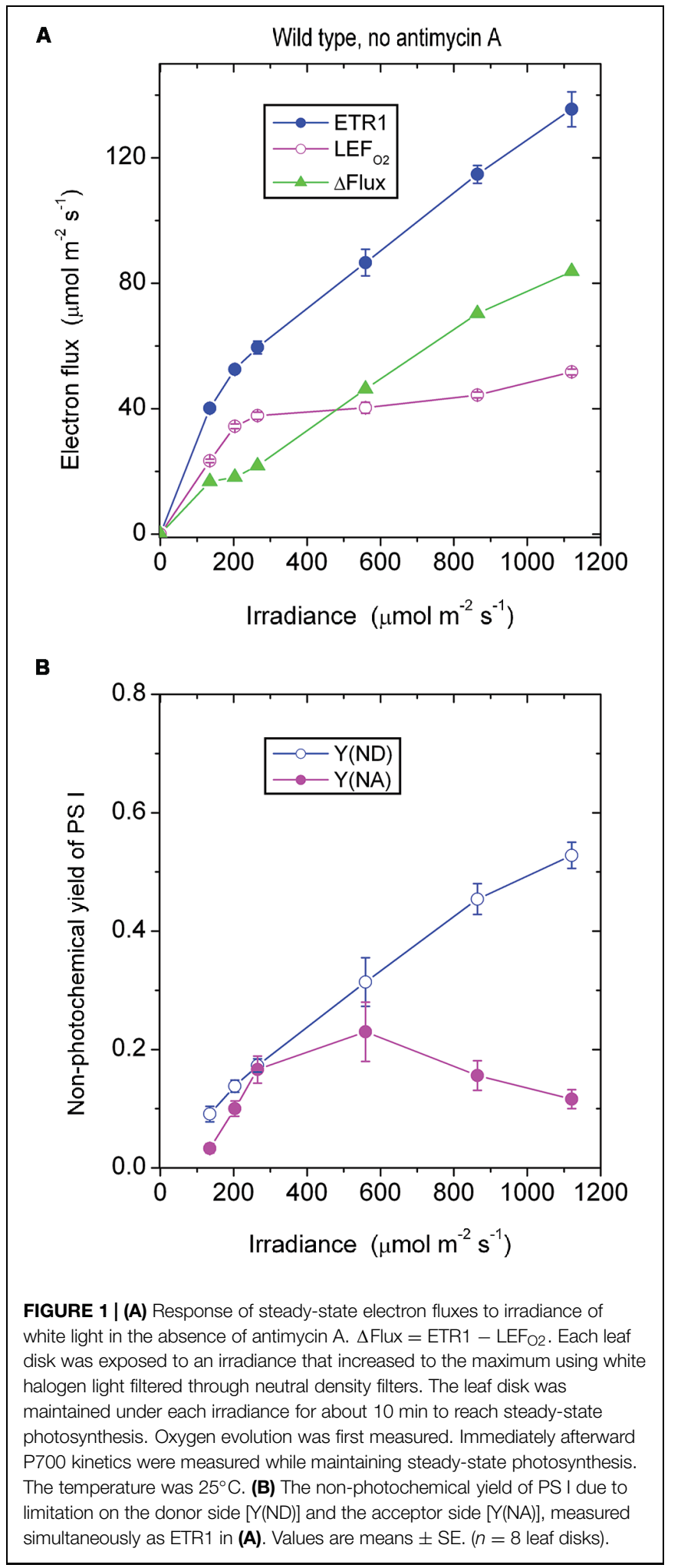

In both the pgr5 mutant (Figure 4A) and the wild type (Figure 2A), in the presence of antimycin $\mathrm{A}$ and at irradiance $559 \mu \mathrm{mol}$ photons $\mathrm{m}^{-2} \mathrm{~s}^{-1}$, there was a sizable $\Delta$ Flux (14$16 \mu \mathrm{mol}$ electrons $\mathrm{m}^{-2} \mathrm{~s}^{-1}$. Since it appears that there was

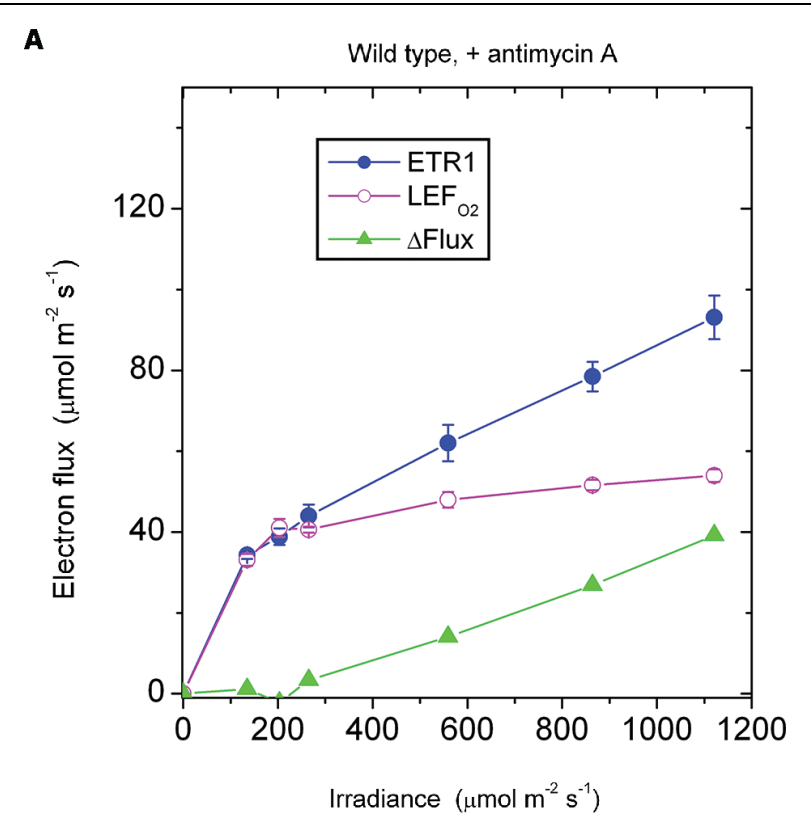

$\mathbf{B}$

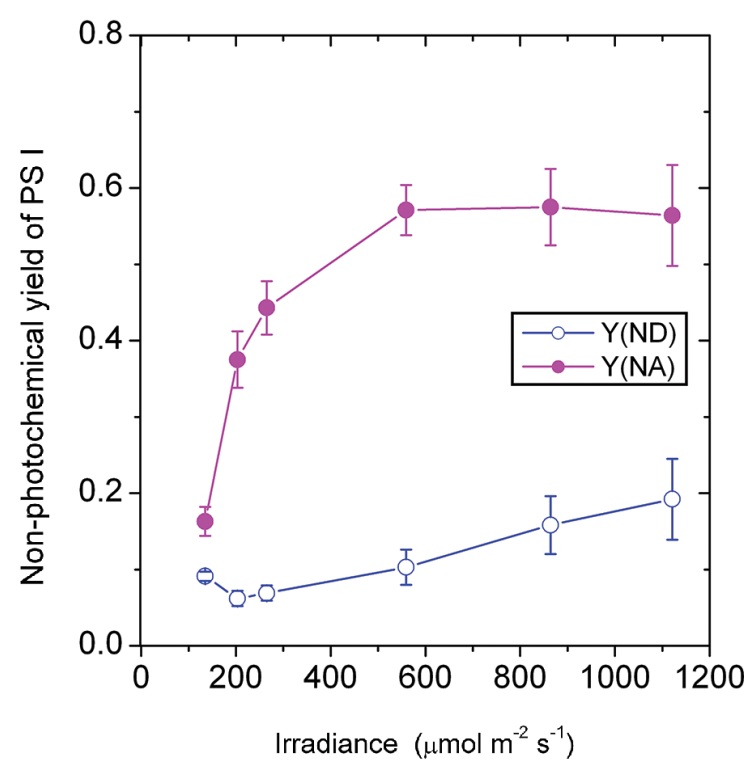

FIGURE 2 | Response of steady-state ETR1, LEF ${ }_{\mathrm{O} 2}$ and $\Delta$ Flux (A), and $Y(N D)$ and $Y(N A)(B)$ in wild-type leaf disks to irradiance in the presence of antimycin A. Values are means \pm SE. ( $n=$ leaf disks). Other conditions are as in Figure $\mathbf{1 .}$

little or no pseudo-cyclic electron flux at this irradiance even when $\mathrm{Y}(\mathrm{NA})$ was much higher (Figure 3A), this sizable $\Delta$ Flux is attributed to charge recombination. At this irradiance of $559 \mu$ mol photons $\mathrm{m}^{-2} \mathrm{~s}^{-1}, \mathrm{Y}(\mathrm{ND})=0.1$, which was apparently sufficient to enable charge recombination to take place, thereby inducing a substantial $\Delta$ Flux in both the pgr5 mutant and the wild type.

Comparing the absence (Figure 3B) or presence (Figure 4B) of antimycin $\mathrm{A}$ in the pgr5 mutant, there was a clear difference 


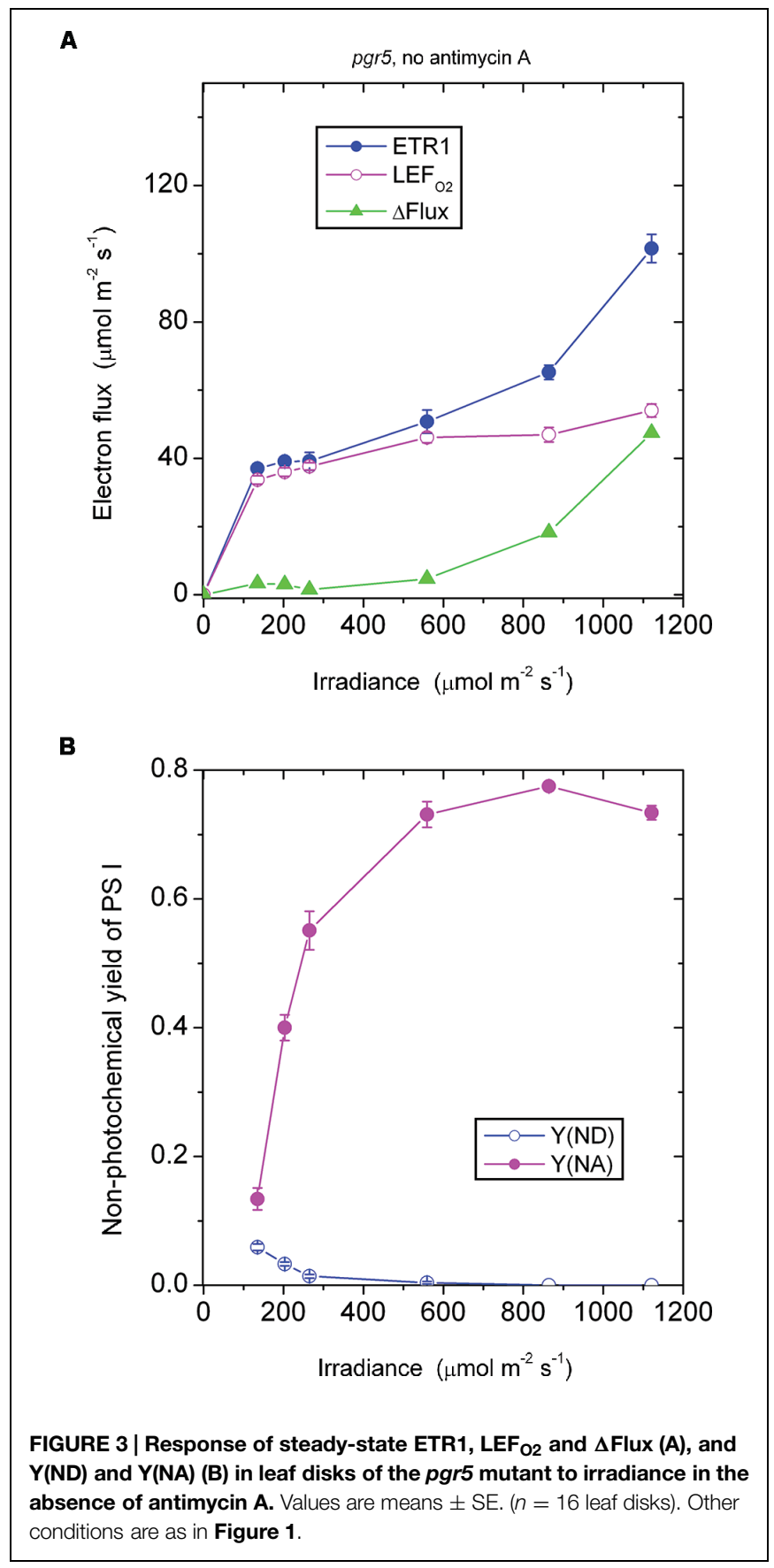

at the lowest irradiance, $135 \mu \mathrm{mol}$ photons $\mathrm{m}^{-2} \mathrm{~s}^{-1}$ : $\mathrm{Y}(\mathrm{NA})$ was only 0.13 in the absence, but 0.37 in the presence of antimycin A. Perhaps the pgr5 mutant, in the absence of antimycin A, was still capable of a small (antimycin A-sensitive) CEF which, at $135 \mu \mathrm{mol}$ photons $\mathrm{m}^{-2} \mathrm{~s}^{-1}$, was able to maintain a largely oxidized state of electron carriers on the acceptor side. Nevertheless, when the irradiance increased further, this small CEF appeared to be abolished because of poor redox poising, $\mathrm{Y}(\mathrm{ND})$ approaching zero. At the same time, the acceptor side of PS I was mostly reduced, Y(NA) increasing to nearly 0.8 at the high irradiances.

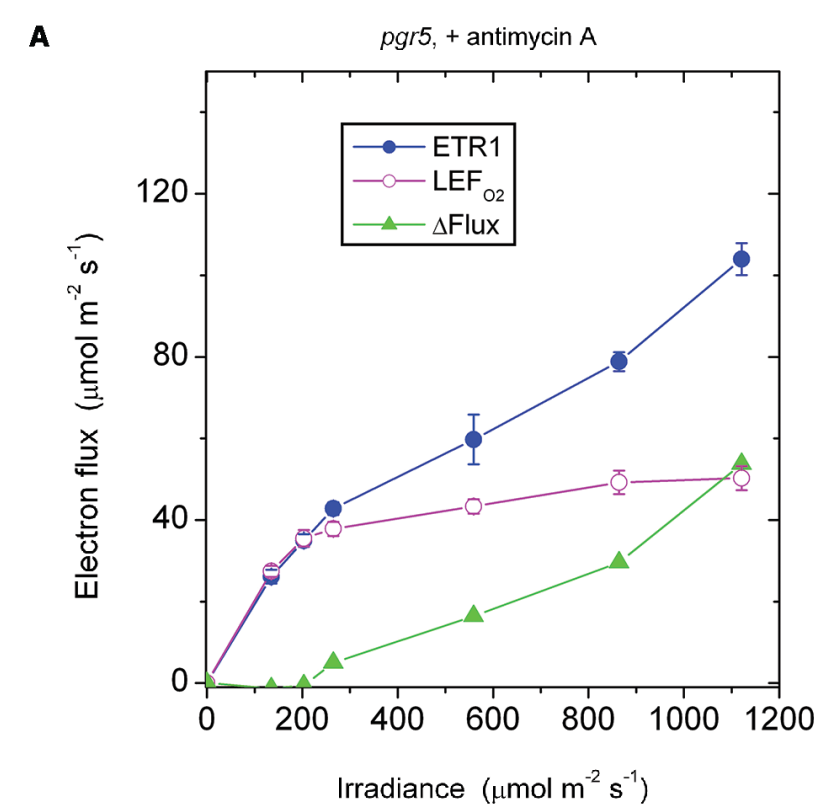

B

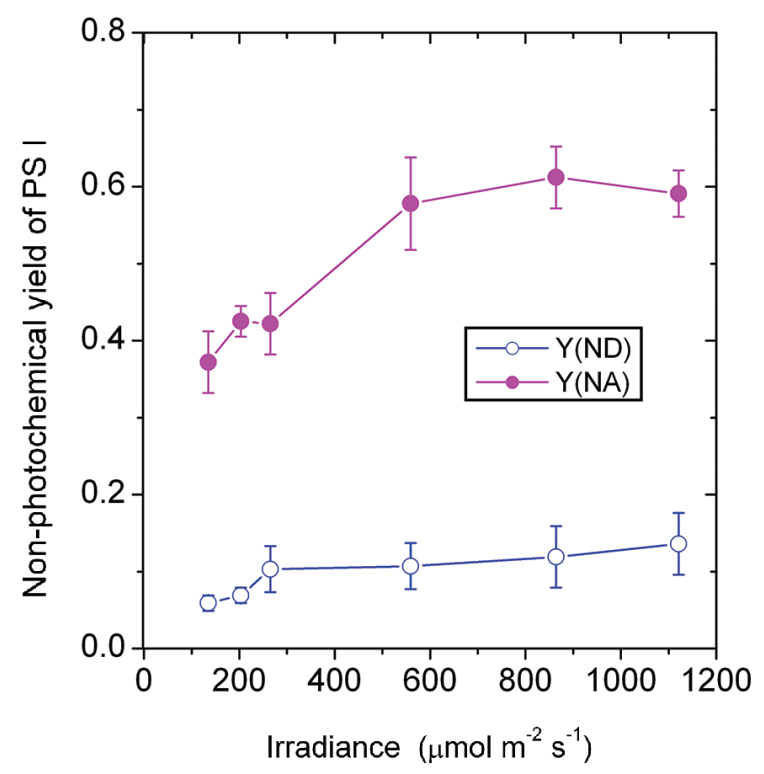

FIGURE 4 | Response of steady-state ETR1, LEF O2, and $\triangle$ Flux (A), and $Y(N D)$ and $Y(N A)(B)$ in leaf disks of the pgr5 mutant to irradiance in the presence of antimycin A. Values are means \pm SE. ( $n=7$ leaf disks). Other conditions are as in Figure $\mathbf{1 .}$

Interestingly, when antimycin A was present in the pgr5 mutant which hardly performs any CEF in the absence of antimycin $\mathrm{A}, \mathrm{Y}(\mathrm{ND})$ was increased while $\mathrm{Y}(\mathrm{NA})$ was lowered after light saturation of linear electron flow, compared with the absence of the inhibitor. One possibility is that the binding of antimycin A somehow increased the Mehler reaction and/or plastid terminal oxidase (PTOX) reaction in the pgr5 mutant; both reactions would increase $\mathrm{Y}(\mathrm{ND})$ and decrease $\mathrm{Y}(\mathrm{NA})$. PTOX is thought to act as a $\mathrm{PQH}_{2}$ water oxidoreductase (Johnson et al., 


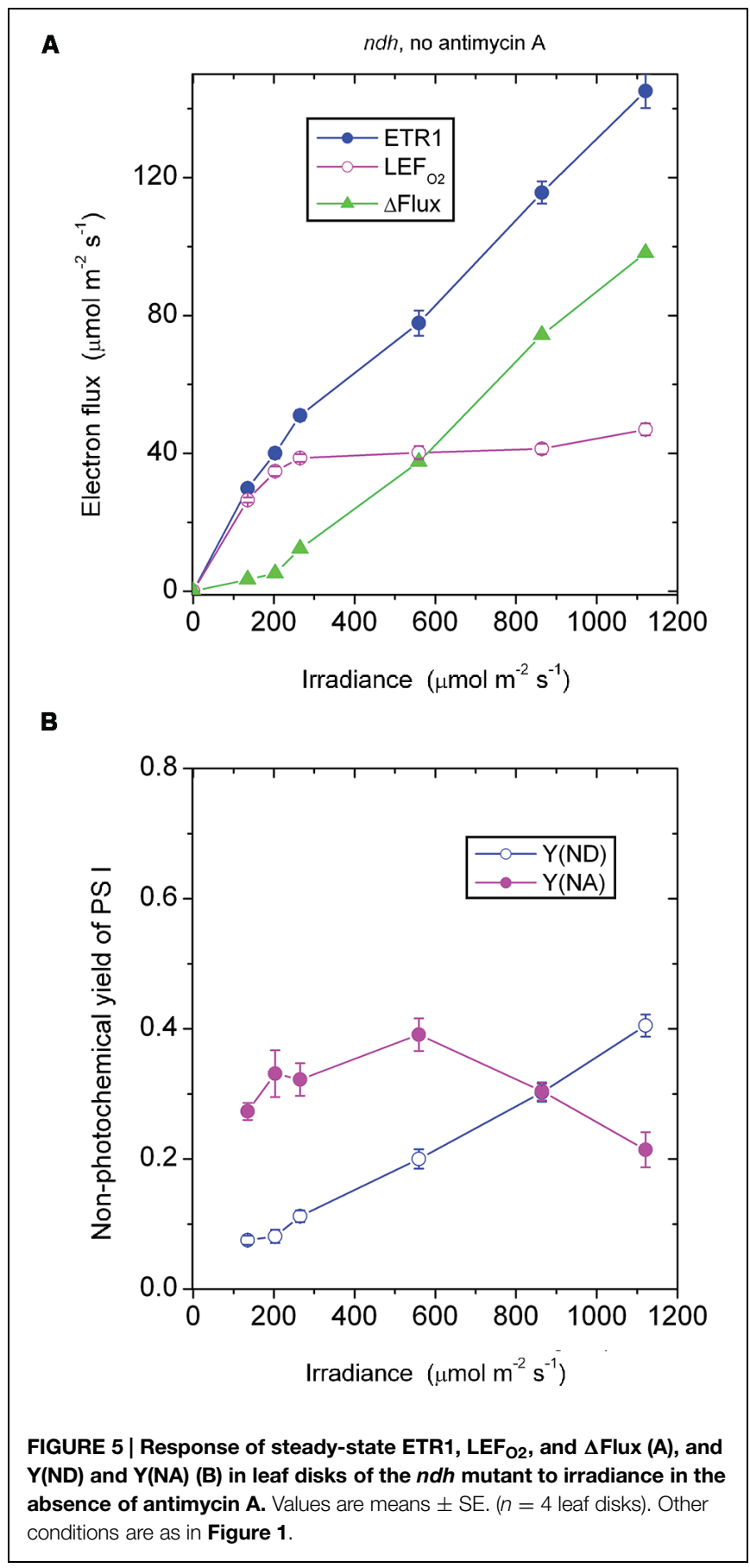

2014); if the superoxide formed in its reaction goes through in a complete water-water cycle, the linear electron flux measured by oxygen evolution is unaffected. Neither does the PTOX reaction affect the electron flux through PS I, so $\Delta$ Flux does not involve the PTOX reaction. However, electrons are shunted away by PTOX before reaching PS I, so that P700 is more oxidized, and the acceptor side less reduced.

The responses of $\mathrm{Y}(\mathrm{ND})$ and $\mathrm{Y}(\mathrm{NA})$ of the pgr5 mutant (in which CEF is mostly inhibited even in the absence of antimycin A) to the treatment with antimycin A differed from the responses

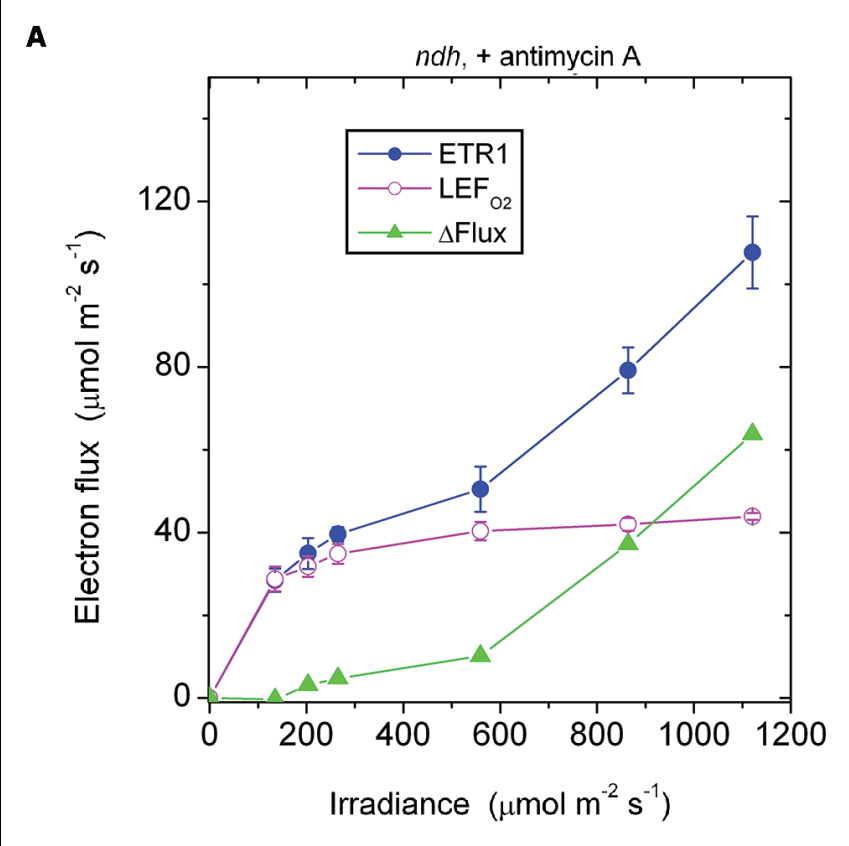

$\mathbf{B}$

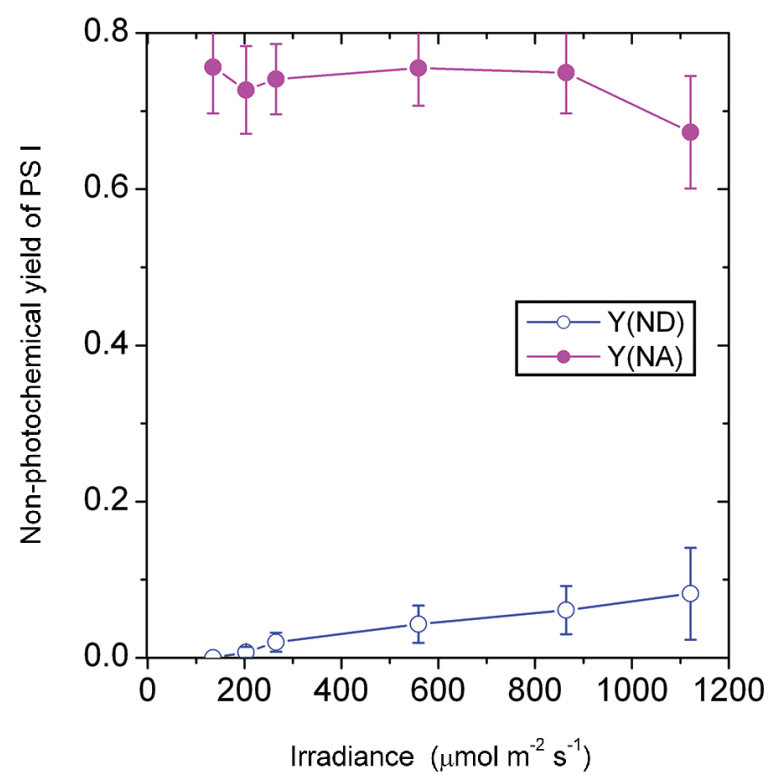

FIGURE 6 | Response of steady-state ETR1, LEF $_{\mathrm{O} 2}$ and $\triangle \mathrm{Flux}(\mathrm{A})$, and $Y(N D)$ and $Y(N A)$ (B) in leaf disks of the ndh mutant to irradiance in the presence of antimycin A. Values are means \pm SE. ( $n=3$ leaf disks). Other conditions are as in Figure 1.

in the wild type and (see later) the $n d h$ mutant. In both the wild type and the $n d h$ mutant, antimycin A decreased Y(ND) but increased Y(NA). This can be rationalized in two ways. First, CEF was inhibited by antimycin A, so that electrons accumulated on the acceptor side, thereby increasing Y(NA). Second, the lower trans-thylakoid $\mathrm{pH}$ gradient on inhibition of CEF allowed electrons to be transferred from $\mathrm{PQH} 2$ more readily through to $\mathrm{P} 700^{+}$, thereby decreasing $\mathrm{Y}(\mathrm{ND})$. 


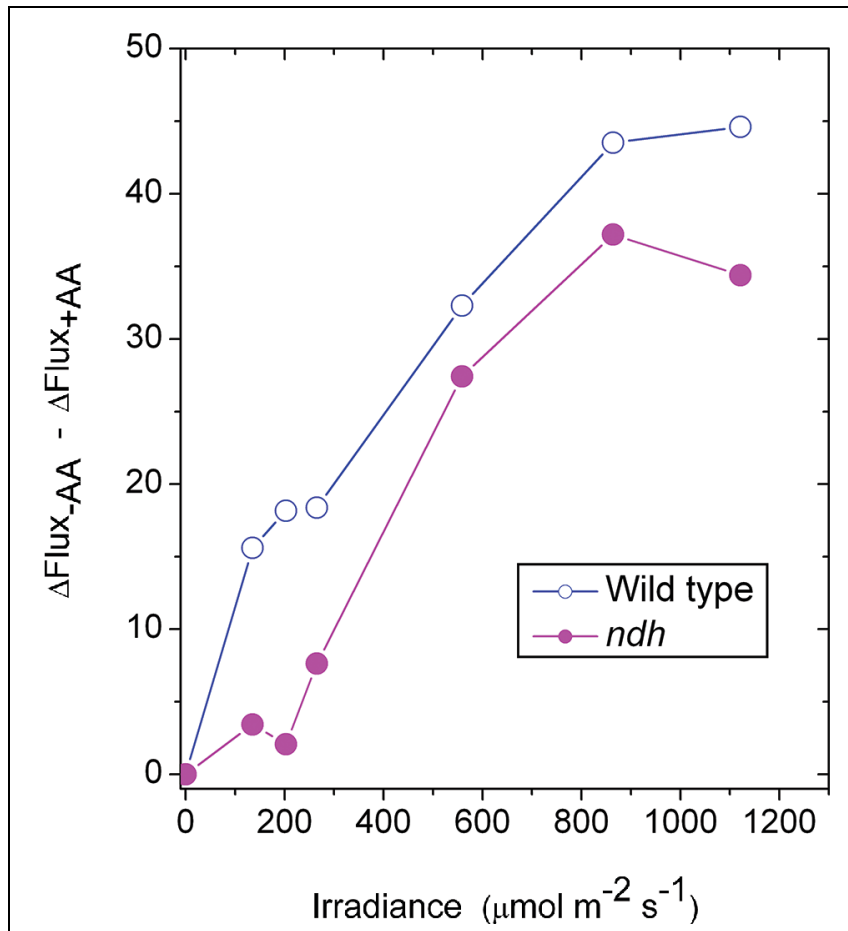

FIGURE 7 | The difference between $\triangle$ Flux in the absence of antimycin (-AA) and the presence of antimycin $A(+A A)$, representing an underestimate of the component of CEF inhibitable by antimycin $A$, is plotted against irradiance. The data are derived from Figures $1 \mathbf{A}$ and $\mathbf{2 A}$ for the wild type and from Figures $\mathbf{5 A}$ and $\mathbf{6 A}$ for the ndh mutant.

\section{The ndh Mutant}

In the absence of antimycin $A$, the $n d h$ mutant should still be capable of generating the CEF that is sensitive to antimycin A. As expected, $\Delta$ Flux increased steadily when the irradiance was above $203 \mu \mathrm{mol}$ photons $\mathrm{m}^{-2} \mathrm{~s}^{-1}$ (Figure 5A). This component of CEF maintained electron carriers on the acceptor side of PS I in a partially oxidized state, $\mathrm{Y}(\mathrm{NA})$ being between 0.2 and 0.4 (Figure 5B).

At an irradiance $\leq 203 \mu \mathrm{mol}$ photons $\mathrm{m}^{-2} \mathrm{~s}^{-1}, \Delta$ Flux in the $n d h$ mutant in the absence of antimycin A was low (Figure 5A), considerably lower than $\Delta$ Flux in the wild type in the absence of antimycin A (Figure 1A). It seems that NDH, which is present in the wild type, enhanced the antimycin A-sensitive component of CEF in the wild type, perhaps through redox regulation.

In the presence of antimycin $A$, the $n d h$ mutant showed a large acceptor side limitation, Y(NA) being 0.7-0.75 throughout the irradiance range. In particular, even when the irradiance was $135 \mu$ mol photons $\mathrm{m}^{-2} \mathrm{~s}^{-1}, \mathrm{Y}(\mathrm{NA})$ reached 0.76 (Figure 6B). By comparison, $\mathrm{Y}(\mathrm{NA})$ was only 0.37 in the pgr5 mutant in the presence of antimycin $\mathrm{A}$ and at the same irradiance (Figure 4B). An obvious difference between (a) the $n d h$ mutant in the presence of antimycin A and (b) the pgr5 mutant in the presence of antimycin $\mathrm{A}$ is that the latter has $\mathrm{NDH}$ activity. It appears that when NDH-mediated CEF is permitted, overreduction of the acceptor side is prevented. Thus, NDH may act as a safety valve when the stroma or, indeed, the acceptor side of PS I, is highly reduced; that is, NDH may contribute to redox homeostasis in chloroplasts at low irradiance (Shikanai, 2014).

\section{The Antimycin A-Sensitive Component of ETR1}

It may be instructive to estimate the magnitude of the antimycin A-sensitive component of ETR1. In the case of the wild type, the presence of antimycin $A(+A A)$ gave a residual $\Delta$ Flux $_{+\mathrm{AA}}$ that is in general contributed by charge recombination, pseudo-cyclic electron flow and, possibly, the $\mathrm{NDH}$-dependent cyclic flux (Figure 2A). Subtracting $\Delta$ Flux $_{+\mathrm{AA}}$ (Figure 2A) from $\Delta$ Flux $_{-A A}$ (Figure 1A) gives an estimate of the antimycin A-sensitive component of ETR1. However, $\left(\Delta\right.$ Flux $_{+\mathrm{AA}}-\Delta$ Flux $\left._{-\mathrm{AA}}\right)$ is an underestimate, since in the absence of antimycin $\mathrm{A}$, the contributions from charge recombination and pseudo-cyclic electron flow could well have been smaller because of competition from CEF for electrons. Even when underestimated, the antimycin A-sensitive component of ETR1 was 15-18 $\mu$ mol electrons $\mathrm{m}^{-2} \mathrm{~s}^{-1}$ at the three low irradiances, peaking at $45 \mu \mathrm{mol}$ electrons $\mathrm{m}^{-2} \mathrm{~s}^{-1}$ at $864 \mu \mathrm{mol}$ photons $\mathrm{m}^{-2} \mathrm{~s}^{-1}$ (Figure 7), where it is similar to the light-saturated $\mathrm{LEF}_{\mathrm{O} 2}$.

In the case of the $n d h$ mutant, $\left(\Delta\right.$ Flux $_{+\mathrm{AA}}-\Delta$ Flux $\left._{-\mathrm{AA}}\right)$ was only $4 \mu \mathrm{mol}$ electrons $\mathrm{m}^{-2} \mathrm{~s}^{-1}$ when averaged over the lowest three irradiances, much lower than in the wild type. This suggests that the presence of $\mathrm{NDH}$ might have promoted the antimycin A-sensitive CEF in the wild type at low irradiance, perhaps via redox regulation (Martin et al., 2015). At the second highest irradiances, $\left(\Delta\right.$ Flux $_{+\mathrm{AA}}-\Delta$ Flux $\left._{-\mathrm{AA}}\right)$ reached a peak value of $36 \mu \mathrm{mol}$ electrons $\mathrm{m}^{-2} \mathrm{~s}^{-1}$. Thus, both the wild type and the $n d h$ mutant were capable of antimycin A-sensitive $\mathrm{CEF}$ at rates comparable to $\mathrm{LEF}_{\mathrm{O} 2}$ at high irradiance. Further, large increases in antimycin A-sensitive CEF occurred at irradiances $\left(\sim 200 \mu \mathrm{mol}\right.$ photons $\left.\mathrm{m}^{-2} \mathrm{~s}^{-1}\right)$ at which $\mathrm{LEF}_{\mathrm{O} 2}$ had been mostly light-saturated. Interestingly, the difference between $\left(\Delta\right.$ Flux $_{+\mathrm{AA}}-\Delta$ Flux $\left._{-\mathrm{AA}}\right)$ of the wild type and that of the $n d h$ mutant was $10 \mu \mathrm{mol}$ electrons $\mathrm{m}^{-2} \mathrm{~s}^{-1}$ (approximately $25 \%$ of $\mathrm{LEF}_{\mathrm{O} 2}$ ), averaged over the entire irradiance range; this could be the cyclic electron flux contributed by NDH, indirectly (for example, by redox regulation that enhances antimycin A-sensitive CEF) or directly.

\section{Conclusion}

A simple non-intrusive method is here presented that estimates whole-tissue $\Delta$ Flux under white light in $\mathrm{CO}_{2}$-enriched air. Application of the method to leaf disks of the wild type and the pgr5 and $n d h$ mutants of Arabidopsis yielded semi-quantitative estimates of (1) the antimycin A-sensitive CEF, (2) contribution of $\mathrm{NDH}$ to ETR1 and (3) possible contributions of charge recombination and/or pseudo-cyclic electron transport to the total electron flux through PS I, at varied irradiance. The electron fluxes through PS I in low-light-acclimated leaves exposed to unusually high light, unfortunately, have many components which cannot be easily dissected quantitatively. 


\section{Acknowledgments}

We are grateful to Professor Toshiharu Shikanai (Kyoto University) for kindly providing seeds of the pgr5 and $n d h$ mutants. This work was supported by a China Scholarship

\section{References}

Allen, J. F. (2003). Cyclic, pseudocyclic and noncyclic photophosphorylation: new links in the chain. Trends Plant Sci. 8, 15-19. doi: 10.1016/S13601385(02)00006-7

Alric, J. (2010). Cyclic electron flow around photosystem I in unicellular green algae. Photosynth. Res. 106, 47-56. doi: 10.1007/s11120-010-9 566-4

Arnon, D. I., Whatley, F. R., and Allen, M. B. (1955). Vitamin K as a cofactor of photosynthetic phosphorylation. Biochim. Biophys. Acta 16, 607-608. doi: 10.1016/0006-3002(55)90295-X

Bendall, D. S., and Manasse, R. (1995). Cyclic photophosphorylation and electron transport. Biochim. Biophys. Acta 1229, 23-38. doi: 10.1016/00052728(94)00195-B

Bukhov, N., and Carpentier, R. (2004). Alternative Photosystem I-driven electron transport routes: mechanisms and functions. Photosynth. Res. 82, 17-33. doi: 10.1023/B:PRES.0000040442.59311.72

Hertle, A. P., Blunder, T., Wunder, T., Pesaresi, T., Pribil, M., Armbruster, U., et al. (2013). PGRL1 is the elusive ferredoxin-plastoquinone reductase in photosynthetic cyclic electron flow. Mol. Cell 49, 511-523. doi: 10.1016/j.molcel.2012.11.030

Huang, W., Zhang, S. B., and Cao, K. F. (2011). Cyclic electron flow plays an important role in photoprotection of tropical tress illuminated at temporal chilling temperature. Plant Cell Physiol. 52, 297-305. doi: 10.1093/pcp/p cq166

Johnson, G. N. (2005). Cyclic electron transport in C3 plants: fact or artefact? J. Exp. Bot. 56, 407-416. doi: 10.1093/jxb/eri106

Johnson, G. N., Cardol, P., Minagawa, J., and Finazzi, G. (2014) "Regulation of electron transport in photosynthesis," in "Plastid Biology," Advances in Plant Biology, Vol. 5, eds S. M. Theg and F.-A. Wollman (New York, NY: SpringerVerlag New York), 437-464.

Joliot, P., and Joliot, A. (2006). Cyclic electron flow in C3 plants. Biochim. Biophys. Acta 1757, 362-368. doi: 10.1016/j.bbabio.2006.02.018

Klughammer, C., and Schreiber, U. (2008). Saturation Pulse Method for Assessment of Energy Conversion in PS I. Available at: http://www.walz.com/ejournal/pdfs/ PAN07002.pdf

Kou, J., Takahashi, S., Oguchi, R., Fan, D. -Y., Badger, M. R., and Chow, W. S. (2013). Estimation of the steady-state cyclic electron flux in white light, CO2enriched air and other varied conditions. Funct. Plant Biol. 40, 1018-1028. doi: 10.1071/FP13010

Kramer, D. M., and Evans, J. R. (2011). The importance of energy balance in improving photosynthetic productivity. Plant Physiol. 155, 70-78. doi: $10.1104 /$ pp. 110.166652

Leister, D., and Shikanai, T. (2013). Complexities and protein complexes in the antimycin A-sensitive pathway of cyclic electron flow in plants. Front. Plant Sci. 4:161. doi: 10.3389/fpls.2013.00161
Council Fellowship to JK, a Knowledge Innovation Program of the Chinese Academy of Sciences grant (KZCX2-XB3-09-02) to D-YF, and grants from the Australian Research Council to WC (DP1093872) and to MRB (The Centre of Excellence for Translational Photosynthesis, CE140100015).

Martin, M., Noarbe, D. M., Serrot, P. H., and Sabater, B. (2015). The rise of the photosynthetic rate when light intensity increases is delayed in ndh genedefective tobacco at high but not at low $\mathrm{CO} 2$ concentrations. Front. Plant Sci. 6:34. doi: 10.3389/fpls.2015.00034

Miyake, C. (2010). Alternative electron flows (water-water cycle and cyclic electron flow around PS I) in photosynthesis: molecular mechanisms and physiological functions. Plant Cell Physiol. 51, 1951-1963. doi: 10.1093/pcp/pcq173

Munekage, Y., Hashimoto, M., Miyake, C., Tomizawa, K. I., Endo, T., Tasaka, M., et al. (2004). Cyclic electron flow around photosystem I is essential for photosynthesis. Nature 429, 579-582. doi: 10.1038/nature02598

Munekage, Y., Hojo, M., Meurer, J., Endo, T., Tasaka, M., and Shikanai, T. (2002). PGR5 is involved in cyclic electron flow around photosystem I and is essential for photoprotection in Arabidopsis. Cell 110, 361-371. doi: 10.1016/S00928674(02)00867-X

Nandha, B., Finazzi, G., Joliot, P., Hald, S., and Johnson, G. N. (2007). The role of PGR5 in the redox poising of photosynthetic electron transport. Biochim. Biophys. Acta 1767, 1252-1259. doi: 10.1016/j.bbabio.2007.07.007

Shen, Y.-K. (1990). "Some factors limiting photosynthesis in nature," in Current Research in Photosynthesis, Vol. 4, ed. M. Baltscheffsky (Dordrecht: Kluwer Academic Publishers), 843-850.

Shikanai, T. (2007). Cyclic electron transport around photosystem I: genetic approaches. Annu. Rev. Plant Biol. 58, 199-217. doi: 10.1146/annurev.arplant.58.091406.110525

Shikanai, T. (2014). Central role of cyclic electron transport around photosystem I in the regulation of photosynthesis. Curr. Opion. Biotechnol. 26, 25-30. doi: 10.1016/j.copbio.2013.08.012

Siebke, K., von Caemmerer, S., Badger, M. R., and Furbank, R. T. (1997). Expressing an $\mathrm{RbcS}$ antisense gene in transgenic Flaveria bidentis leads to an increased quantum requirement for CO2 fixed in Photosystems I and II. Plant Physiol. $115,1163-1174$.

Takahashi, S., Milwood, S. E., Fan, D. Y., Chow, W. S., and Badger, M. R. (2009). How does cyclic electron flow alleviate photoinhibition in Arabidopsis? Plant Physiol. 149, 1560-1567. doi: 10.1104/pp.108.134122

Conflict of Interest Statement: The Guest Associate Editor Wei Huang declares that, despite being affiliated with the same institution as the author Da-Yong Fan, the review process was handled objectively. The authors declare that the research was conducted in the absence of any commercial or financial relationships that could be construed as a potential conflict of interest.

Copyright (c) 2015 Kou, Takahashi, Fan, Badger and Chow. This is an open-access article distributed under the terms of the Creative Commons Attribution License (CC BY). The use, distribution or reproduction in other forums is permitted, provided the original author(s) or licensor are credited and that the original publication in this journal is cited, in accordance with accepted academic practice. No use, distribution or reproduction is permitted which does not comply with these terms. 